\title{
ANATOMIA ÓSSEA E MUSCULAR DO CÍNGULO ESCAPULAR E BRAÇO DE Tapirus terrestris (PERISSODACTYLA: TAPIRIDAE)
}

\section{BONE AND MUSCULAR ANATOMY OF THE SCAPULAR CINGULUM AND ARM IN Tapirus terrestris (PERISSODACTYLA: TAPIRIDAE)}

\author{
Saulo Gonçalves Pereira ${ }^{1}$ \\ André Luíz Quagliatto Santos ${ }^{2}$ \\ Daniela Cristina Silva Borges ${ }^{1}$ \\ Rogério Rodrigues de Souza ${ }^{3}$ \\ Priscilla Rosa Quaioz ${ }^{1}$ \\ ${ }^{1}$ Pós-graduandos da Universidade Federal de Uberlândia, Uberlândia, MG. Brasil. \\ saulobiologo@yahoo.com.br \\ ${ }^{2}$ Professor Doutor da Universidade Federal de Uberlândia, Uberlândia, MG. Brasil. \\ ${ }^{3}$ Mestre em Ciência Animal pela Universidade Federal de Uberlândia, Uberlândia, MG. Brasil.
}

\section{Resumo:}

Tapirus terrestris (Linneaus, 1758) é um mamífero encontrado na América do Sul e em quase todos os biomas brasileiros. O objetivo deste estudo foi descrever a anatomia óssea e muscular do cíngulo escapular e braço de Tapirus terrestris e comparar com outras espécies de mamíferos, principalmente equinos. Utilizaram-se quatro animais doados ao Laboratório de Ensino e Pesquisa em Animais Silvestres da Universidade Federal de Uberlândia, após óbito sem trauma. Os ossos foram minuciosamente analisados e descritos e os músculos dissecados, analisados e descritos de acordo com as técnicas usuais em anatomia macroscópica. O esqueleto do cíngulo escapular e braço de Tapirus terrestris é constituído pelos ossos: escápula e úmero, os músculos da face lateral da escápula são o m. subclávio, $\mathrm{m}$. deltóide, $\mathrm{m}$. supraespinhal, $\mathrm{m}$. infraespinhal e $\mathrm{m}$. redondo menor, $\mathrm{m}$. subescapular, $\mathrm{m}$. redondo maior, $\mathrm{m}$. coracobraquial, $\mathrm{m}$. articular do ombro, $\mathrm{m}$. bíceps do braço, $\mathrm{m}$. braquial, $\mathrm{m}$. tríceps do braço, $\mathrm{m}$. tensor da fáscia do antebraço, $\mathrm{m}$. ancôneo. $\mathrm{O}$ padrão ósseo e muscular encontrado é similar ao cavalo (Equus caballus) T. terrestris apresenta características ósseas e musculares de um animal adaptado ao deslocamento e a natação eventual com acidentes ósseos evidentes e musculatura desenvolvida.

Palavras-chave: escápula; mamíferos; morfologia descritiva.

\begin{abstract}
:
Tapirus terrestris (Linneaus, 1758) is a mammal found in South America and in almost all Brazilian biomes. The aim of this study was to describe the anatomy of bone and muscle of the scapular cingulum and arm of Tapirus terrestris and compare it with other species of mammals, especially equines. We used four animals donated to the Laboratory of Education and Research of Wild Animals of the Federal University of Uberlândia, after their death with no trauma. The bones were carefully analyzed, described and the muscles were dissected, analyzed and described in accordance with the usual techniques of gross anatomy. The skeleton of the scapular cingulum and arm of Tapirus terrestris is formed by scapula and humerus bones, the lateral muscles of the scapula are subclavian $\mathrm{m}$., deltoid $\mathrm{m}$. supraspinatus $\mathrm{m}$. and infraspinatus, teres minor m., subscapularis m., teres major m., coracobrachialis m., shoulder joint m., biceps brachii m., brachial $\mathrm{m}$. triceps, forearm tensor fasciae $\mathrm{m}$., anconeus $\mathrm{m}$. The muscular and bone standard found is similar
\end{abstract}


to the horse (Equus caballus) T. terrestris has bone and muscle characteristics of a suitable animal to displacement and eventual swimming with obvious bone accidents and developed muscles .

Keywords: descriptive morphology; mammals; scapula.

Recebido em: 02 fevereiro 2014.

Aceito em: 07 janeiro 2015.

\section{Introdução}

A anta (Tapirus terrestris - Linnaeus 1758) é um mamífero ungulado que pertence à ordem Perissodactyla $^{(1)}$. Essa ordem é composta por três famílias: Tapiridae (antas), Equidae (cavalos, zebras e burros) e Rhinocerotoidea (rinocerontes) ${ }^{(2)}$. O gênero Tapirus, atualmente, compreende cinco espécies Tapirus terrestris, Tapirus pinchaque, Tapirus bairdii, Tapirus indicus e Tapirus kabomani $^{(3)}$. São encontrados na Terra desde o período Pleistoceno até os dias atuais ${ }^{(4)}$.

Os tapirídeos são classificados na ordem Perissodactyla, subordem Ceratomorpha, superfamília Tapiroides, família Tapiridae e gênero Tapirus. Esses mamíferos têm um número ímpar de dedos (um ou três), cada um com um casco ${ }^{(1)}$. T. terrestris, diferentemente, tem quatro dedos na mão e três no pé. O quarto dedo do membro torácico é menos desenvolvido e eventualmente toca o solo ${ }^{(5)}$. T. terrestris é um dos maiores mamíferos das Américas, distribui-se desde o sul do Brasil, Chaco da Argentina, Paraguai e Bolívia, ao norte até a região Amazônica, oeste da Venezuela e no norte da Colômbia. No Brasil, as antas distribuem-se em quase todos os Biomas ${ }^{(1)}$. São animais herbívoros, encontrados acompanhados apenas durante a época de acasalamento ou durante a amamentação ${ }^{(6)}$. A anatomia interna e fisiologia dos tapirídeos são consideravelmente semelhantes às do cavalo doméstico e de outros Perissodactyla ${ }^{(7)}$.

A descrição morfológica de espécies da fauna silvestre acrescenta um enorme subsídio para o conhecimento desses animais, pois auxilia nas intervenções de ordem clínico-cirúrgica e conservacionistas $^{(8)}$. Descrições anatômicas pormenorizadas contribuem para engrandecer o acervo teórico sobre as espécies, colaborando, dessa maneira, para o enriquecimento das aplicações médicas, terapêuticas e clínicas ${ }^{(9,10)}$.

Visto a importância da anta para o meio ambiente, como dispersor de sementes e regulador ambiental dentro das teias alimentares, e considerando a importância do conhecimento anatômico sobre a espécie para os apontamentos de ordem clínica, cirúrgica e conservacionista, objetivou-se descrever a anatomia óssea e muscular do cíngulo escapular e braço de Tapirus terrestris e comparar com outros animais domésticos e silvestres.

\section{Material e Métodos}

Foram utilizadas peças anatômicas de quatro espécimes adultos doados por um criadouro, após óbito natural sem trauma, ao Laboratório de Ensino e Pesquisa em Animais Silvestres da Universidade Federal de Uberlândia (LAPAS-UFU). A pesquisa foi autorizada pelo Conselho de Ética para Utilização de Animais da UFU (CEUA) sob o parecer 069/12, e está de acordo com a Instrução Normativa 154/2007 do IBAMA. As peças anatômicas foram fixadas em solução aquosa de formaldeído a $10 \%$ e conservadas em cubas opacas contendo a mesma solução. 
Para a descrição dos ossos, os membros de três indivíduos foram desarticulados e pele, vísceras e musculatura associada aos ossos do cíngulo escapular e braço dos espécimes foram retiradas. Posteriormente, os ossos foram macerados em água fervente e colocados em solução de peróxido de hidrogênio por 12 horas. Depois de limpos e secos, os ossos foram identificados, minuciosamente analisados, descritos e comparados com a literatura pertinente, dentro das classes taxonômicas mais próximas.

Para a preparação dos músculos, as peças anatômicas foram cuidadosamente dissecadas preservando-se seus pontos de inserção e fixação, características e sintopia. Para tanto, a pele e o tecido adiposo foram retirados para a exposição dos músculos e demais constituintes anatômicos relacionados ao cíngulo escapular e braço. A nomenclatura adotada está de acordo com o International Committee on Veterinary Gross Anatomical Nomenclature (2012) ${ }^{(11)}$. Para as descrições morfológicas, os dados foram analisados de forma descritiva e comparada, principalmente com equídeos, que são taxonomicamente mais próximos ao animal estudado, além de ruminantes e outros mamíferos selvagens. As imagens foram registradas com câmera digital (Kodak Easy Shere C182, 12 mega pixel) e tratadas pelo software Adobe Photoshop CC 14.

\section{Resultados e Discussão}

O esqueleto do cíngulo escapular e braço da anta é constituído pelos ossos escápula e úmero, respectivamente. $\mathrm{Na}$ espécie estudada, esses ossos são bastante protuberantes e desenvolvidos. $T$. terrestris tem grande capacidade de deslocamento, desenvolvendo seu nicho em grandes áreas ${ }^{(12)}$, sendo assim, os ossos longos, fortes e protuberantes dão auxilio neste deslocamento, assim como $\operatorname{nos}_{\text {equinos }}{ }^{(13)}$.

A escápula de T. terrestris (Figura 1) é um osso plano, ovalado e irregular, que se encontra preso obliquamente à parte cranial da parede torácica e articula-se distalmente com a cabeça do úmero, através da cavidade glenóide, sendo um conector. No equino (Equus caballus), a escápula é um osso triangular ${ }^{(13)}$. Em T. terrestris apresenta duas faces (medial e lateral), duas margens (cranial e caudal) e dois ângulos (cranial, caudal). A mesma configuração é encontrada em equinos e em capivaras (Hydrochoerus hydrochaeris). A escápula tem a função de abrigar os músculos da área do membro torácico, dando-lhes origem. Esses músculos estão agrupados em torno dela.

A face lateral é dividida pela espinha da escápula (Figura 1. II B), que é bastante alongada e proeminente, como nos ruminantes ${ }^{(13)}$. A fossa supraespinhal (Figura 1. II D) é menor, se comparada à fossa infraespinhal (Figura 1. II E). No centro da escápula localiza-se a tuberosidade da escápula (Figura 1. II C), que serve de inserção ao músculo trapézio. Há presença de forame nutrício na região distal desta face (Figura 1. II H). Ressalta-se que, diferente dos ruminantes, $T$. terrestris não possui acrômio ${ }^{(13)}$.

$\mathrm{Na}$ face medial da escápula de T. Terrestres, a fossa subescapular (Figura 1. I J) ocupa aproximadamente $1 / 3$ do osso e possui pequenas protuberâncias na direção medial. Essas mesmas características são muito evidentes no Equus caballus ${ }^{(13)}$. Há a presença de incisura na margem lateral distal (Figura 1. I I), na parte distal localizam-se forames nutrícios de diversos diâmetros (Figura 1. II H). O colo da escápula é liso e encontra-se na parte distal (Figura 1. I E), o processo coracóide é proeminente e a tuberosidade supraglenoidal é ovalada. 


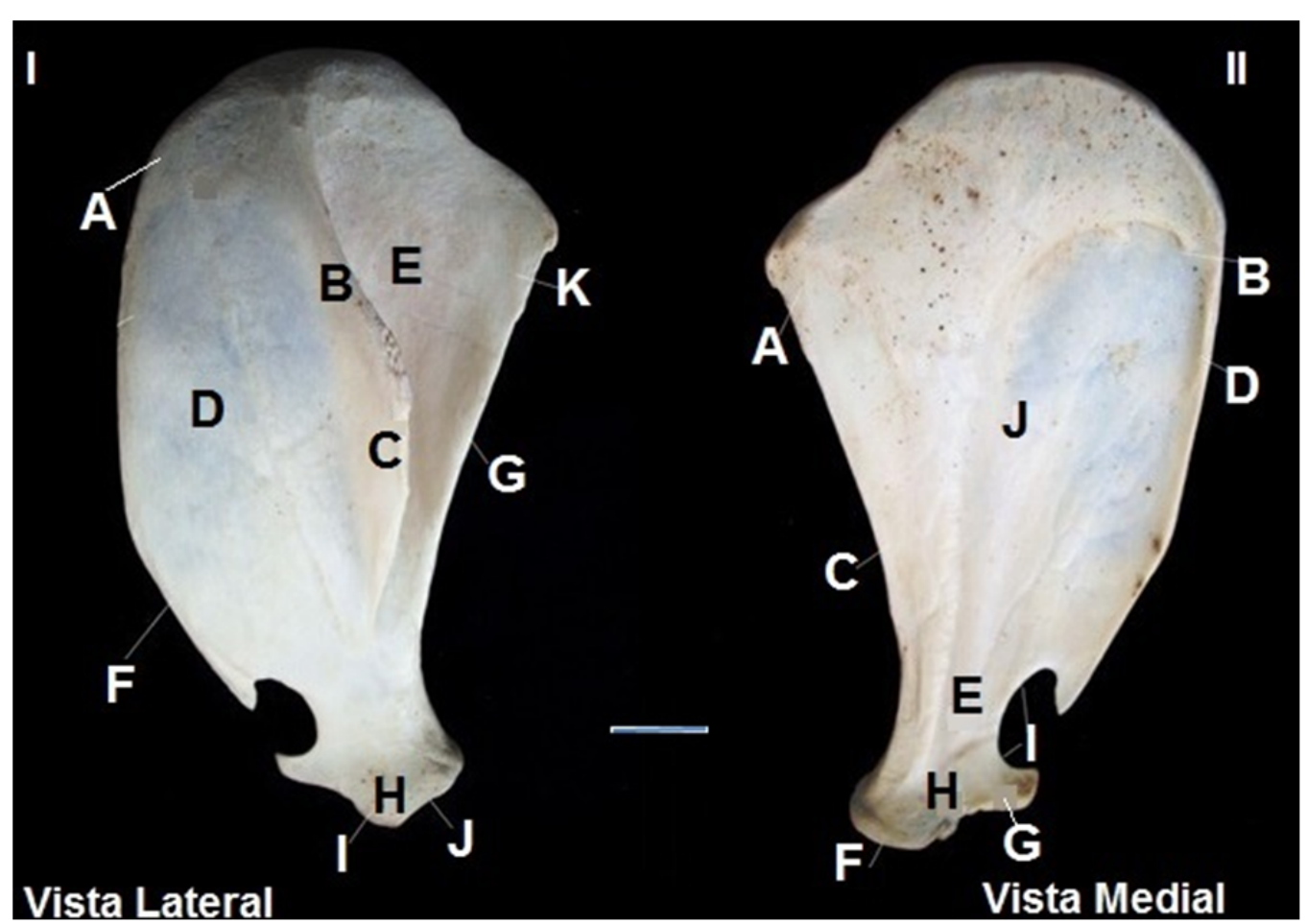

Figura 1: Fotografia da escápula de T. terrestris. (Fonte: Acervo particular. Uberlândia, 2012).

Legenda: I- Vista lateral - (A) ângulo cranial; (B) espinha da escápula; (C) tuberosidade da escápula; (D) fossa supraespinhal; (E) fossa infraespinhal; (F) margem cranial; (G) margem caudal; (H) forame nutrício; (I) tuberosidade supraglenoidal; (J) cavidade glenóide; (K) ângulo caudal. II- Vista Medial - (A) ângulo caudal; (B) ângulo cranial; (C) margem caudal; (D) margem cranial; (E) colo da escápula; (F) cavidade glenóide; (G) tuberosidade supraglenoidal; (H) processo coracóide; (I) incisura na margem lateral distal; (J) fossa subescapular. Barra de Calibração: $1 \mathrm{~cm}$ (figura real $\sim 25 \mathrm{~cm}$ )

O úmero (Figura 2) é o osso que está presente no braço de T. terrestris. É um osso longo típico e como tal é constituído de corpo (diáfise) com extremidades distal e proximal (epífises). Apresenta quatro faces, medial, lateral, caudal e cranial. Possui forma arredondada e articula-se proximalmente com a escápula, através da cavidade glenóide, assim como nos equinos ${ }^{(13)} \mathrm{e}$ distalmente com o rádio e a ulna. Nos quadrúpedes o úmero agrupa os músculos do braço, dando inserção para os músculos originados na escápula.

A cabeça do úmero (Figura 2 IF), estrutura que se articula com a cavidade glenóide, é arredondada e maior que esta cavidade. O colo (Figura 2. I B) é bem aparente e está caudalmente localizado com relação à cabeça do úmero ao lado da tuberosidade maior que também é proeminente (Figura 2 IA). A tuberosidade menor (Figura 2. II L) localiza-se proximalmente a escápula, medialmente ao sulco intertuberal, constituindo, assim, sua parede medial. O sulco intertuberal (Figura 2. II J) é uma região rugosa com a presença de pequenos forames nutrícios em sua parte medial.

O corpo do úmero é cilíndrico e em sua face lateral localiza-se a tuberosidade deltóidea (Figura 2. I C, II H), que possui aspecto rugoso, assim como em Equus caballus ${ }^{(13)}$. A face lateral é lisa com uma breve depressão, o sulco para o músculo braquial (Figura 2. II G).

A face medial é reta, diferentemente dos equinos, nesta face localiza-se uma parte rugosa que é a tuberosidade para o músculo redondo maior (Figura 2. II M), na parte longitudinal do osso, onde há a inserção do músculo redondo maior. $\mathrm{Na}$ face medial do úmero na parte distal, localiza-se um forame nutrício (Figura 2. II N). Na face caudal, distalmente, encontra-se a fossa do olécrano (Figura 2. I E), que é mais profunda se comparada à fossa radial. A face cranial do corpo do úmero 
é levemente triangular e lisa. A tuberosidade para o músculo redondo menor (Figura 2. I D) está localizada em sua parte proximal.

A extremidade distal do osso é formada pelo côndilo que se divide em capítulo (Figura 2. II A), tróclea (Figura 2. II B), fossa radial (Figura 2. II C) e fossa do olécrano (Figura 2. I E), compondo a superfície articular com o rádio e a ulna, sendo o capítulo estreito e localizado lateralmente a tróclea. A fossa radial localiza-se cranialmente à tróclea, é uma depressão rugosa e com presença do forame supracondilar, o epicôndilo medial é arredondado (Figura 2 IID) já o epicôndilo lateral é em formato de espinha (Figura 2 IIE). A tuberosidade do músculo redondo maior é lisa e abriga a inserção desse músculo (Figura 2 II. I).

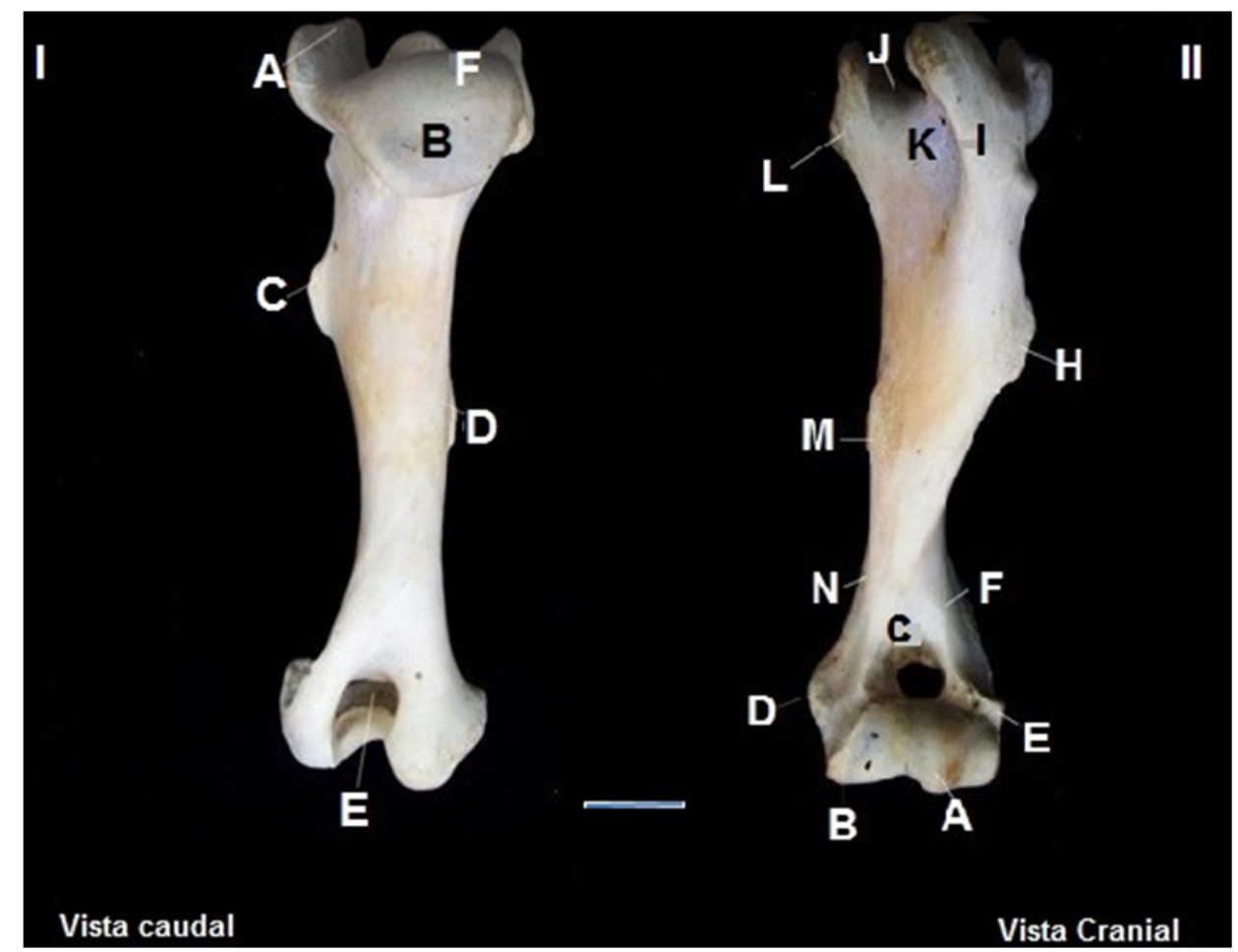

Figura 2: Fotografia do úmero de T. terrestris. (Fonte: Acervo particular. Uberlândia, 2012).

Legenda: I- Vista Caudal - (A) tuberosidade maior; (B) colo; (C) tuberosidade deltóidea; (D) tuberosidade para o músculo redondo menor; (E) fossa do olecrano; (F) cabeça do úmero. II- Vista Cranial - (A) capítulo; (B) tróclea; (C) fossa radial; (D) epidicôndilo medial; (E) epicôndilo lateral; (F) crista do epicôndilo lateral; (G) sulco para o músculo braquial; (H) tuberosidade deltóidea; (I) tuberosidade maior; (J) sulco intertuberal; (K) forame nutrício proximal; (L) tuberosidade menor; (M) tuberosidade para o músculo redondo maior; (N) forame nutrício distal. Barra de Calibração: $1 \mathrm{~cm}$ (figura real $\sim 27 \mathrm{~cm}$ )

Os músculos são fundamentais unidades de trabalho dos animais, e por meio das contrações e relaxamentos, harmonizam os movimentos de flexão, extensão, adução, abdução e rotação ${ }^{(14)}$. Os músculos do cíngulo escapular de $T$. terrestris se originam na escápula e se inserem no úmero; dividem-se na face lateral e face medial da escápula. No ombro estão localizadas duas fáscias, superficial e profunda. A fáscia superficial contém o músculo cutâneo. A fáscia profunda de $T$. terrestris é forte e tendínea, está aderida aos músculos da face lateral da escápula ${ }^{(13)}$. 


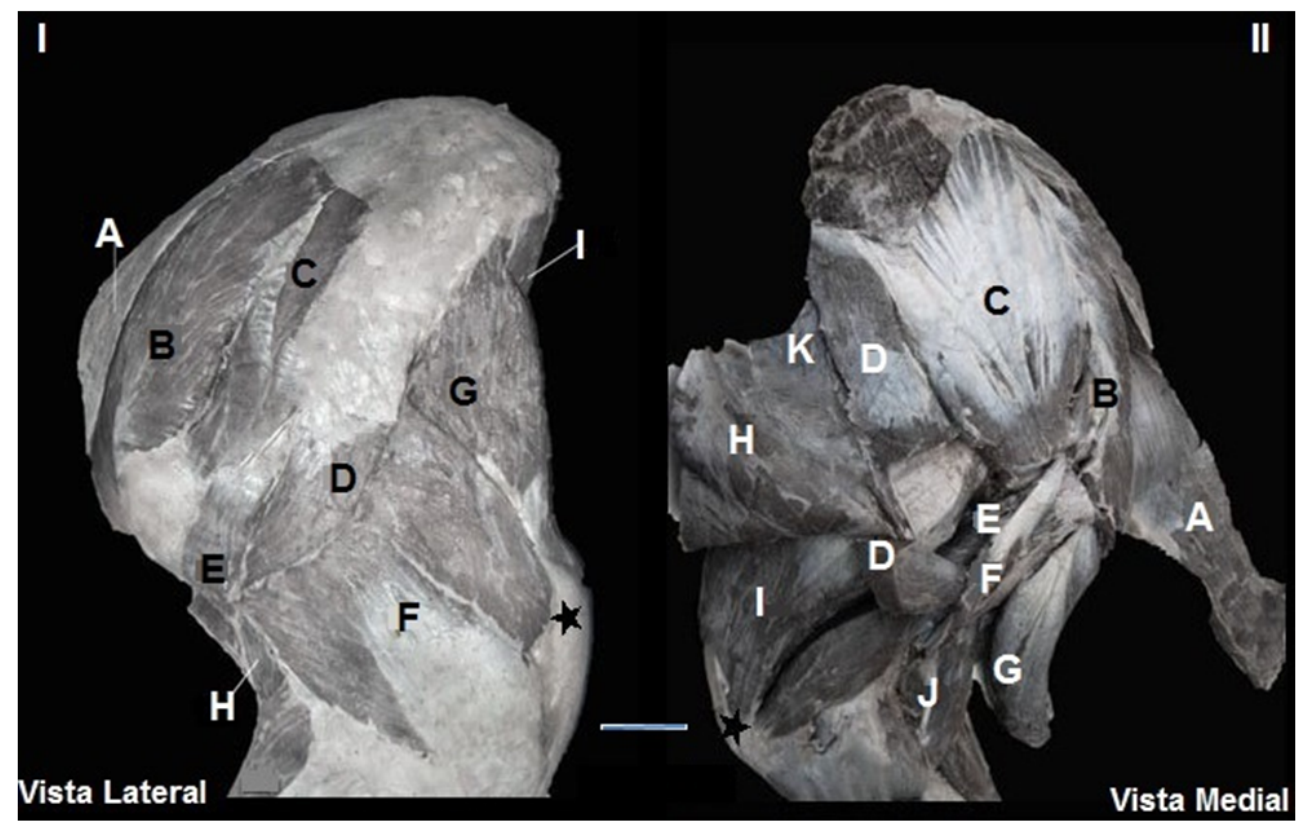

Figura 3: Fotografia dos músculos do cíngulo escapular e braço de T. terrestris, faces lateral e medial, respectivamente. (Fonte: Acervo particular. Uberlândia, 2013).

Legenda: I- Face Lateral - (A) $\mathrm{m}$. subclávio; (B) $\mathrm{m}$. supraespinhal; (C) $\mathrm{m}$. infraespinhal; (D) $\mathrm{m}$. deltóide; (E) $\mathrm{m}$. redondo menor; (F) m. tríceps do braço cabeça lateral; (G) m. tríceps do braço cabeça longa; (H) m. braquial; (I) $\mathrm{m}$. tensor da fáscia do antebraço. II- Face Medial - (A) m. subclávio; (B) m. supraespinhal; (C) $\mathrm{m}$. subescapular; (D) m. redondo maior [parcialmente rebatido]; (E) $\mathrm{m}$. articular do ombro; (F) $\mathrm{m}$. coracobraquial; (G) $\mathrm{m}$. bíceps do braço [parcialmente rebatido]; $(\mathrm{H}) \mathrm{m}$. tensor da fáscia do antebraço [parcialmente rebatido]; (I) $\mathrm{m}$. tríceps do braço cabeça medial; (J) m. braquial; (K). m. grande dorsal [parcialmente rebatido]; $(\star)$ olécrano.

Barra de Calibração: $1 \mathrm{~cm}$ (figura real $\sim 45 \mathrm{~cm}$ )

Os músculos que fazem parte da face lateral da escápula são o m. subclávio, m. deltóide, $\mathrm{m}$. supraespinhal, $\mathrm{m}$. infraespinhal e $\mathrm{m}$. redondo menor.

O m. subclávio (Figura 3. I A) em T. terrestris é um músculo protuberante e volumoso, que se situa cranialmente à articulação glenoumeral, com uma grande quantidade de tecido adiposo. Em equinos este músculo é parte do membro torácico originando-se na parte cranial do esterno. Nos carnívoros está ausente e em ruminantes tem inserção junto ao m. supraespinhal e sua função é fixar a escápula ${ }^{(13)}$.

O m. deltóide (Figura 3. I D) é um músculo arredondado em sua parte média, está localizado, parcialmente, na face lateral da articulação do ombro. A parte caudal está fixada na escápula. Cabe ressaltar que em $T$. terrestris não existe parte acromial como nos bovinos, sendo este músculo muito similar ao do equino ${ }^{(13)}$. A escápula de quati (Nasua nasua) e mão-pelada (Procyon cancrivorus) possui duas partes, escapular e acromial ${ }^{(15)}$.

O m. supraespinhal (Figura 3. I B) tem formato alongado e espesso em toda sua extensão com fibras verticais. Este músculo está envolvido por uma aponeurose fibrosa. Está divido em dois ramos de onde se origina o tendão de origem do $\mathrm{m}$. bíceps do braço.

$\mathrm{O}$ m. infraespinhal de $T$. terrestris (Figura 3. I C) é semelhante ao do equino ${ }^{(13)}$. Localiza-se na fossa infraespinhal da escápula e ocupa a maior parte desta, estendendo-se caudalmente a partir dela. Revestido por uma densa aponeurose que o insere na escápula é dividido por dois estratos. Assim como em Nasua nasua exerce a ação de estender e flexionar a articulação do ombro e girar o braço lateralmente ${ }^{(15)}$.

O m. redondo menor (Figura 3. I E) é pequeno e está situado na margem caudal da escápula, entre os músculos deltóide e infraespinhal, é ligado à cabeça lateral do $\mathrm{m}$. tríceps do braço na parte 
profunda. Apesar de ser chamado de redondo, em T. terrestris tem forma triangular plana, é coberto por uma aponeurose fibrosa, sua origem e inserção são as mesmas do Puma (Puma concolor) ${ }^{(17)}$. Em equinos é um pequeno músculo de pouca importância e fornece as fibras de origem para o $\mathrm{m}$. infraespinhal e a cabeça longa do $\mathrm{m}$. tríceps do braço e em sua parte profunda articula-se com a tuberosidade maior do úmero, o que é percebido também em $T$. terrestris ${ }^{(13)}$.

Os músculos que fazem parte da face medial da escápula ocupam a fossa subescapular e alargam-se tanto cranial como caudalmente, são eles o m. subescapular, m. coracobraquial, m. articular do ombro e m. redondo maior.

O m. subescapular (Figura 3. II C) ocupa toda a extensão da fossa subescapular ${ }^{(13,16-17)}$, exceto as partes dos ângulos cranial e caudal da escápula. É um músculo triangular plano e no ângulo cranial é arredondado, seguindo o formato da escápula de T. terrestris. A aponeurose que cobre o músculo é densa e tendinosa. Em cachorros domésticos (Canis spp.), Nasua nasua e Procyon Cancrivorus, tem a função de estender e aduzir o ombro, o que é uma forte inferência também para $T$. terrestris $^{(15,16)}$.

$\mathrm{O}$ m. redondo maior (Figura 3. II D) é alongado e largo e inserido na face medial do $\mathrm{m}$. tríceps do braço (cabeça medial). Em canis spp., segundo St. Clair ${ }^{(16)}$, em Nasua nasua ${ }^{(15)}$ e em Procyon cancrivorus $^{(17)}$ o músculo redondo maior possui ação de flexionar o ombro e rodar lateralmente o braço, o que também ocorre em $T$. terrestris.

O m. coracobraquial (Figura 3. II F) está localizado na face medial da articulação do ombro e do braço. Está situado caudalmente ao $\mathrm{m}$. redondo maior, assim em cavalos ${ }^{(13)}$.

$\mathrm{O}$ m. articular do ombro (Figura 3. II E) é um pequeno músculo situado na superfície flexora da cápsula da articulação do ombro, imediatamente caudal ao m. tríceps do braço (cabeça medial). Em T. terrestris, este músculo está pouco evidente, assim como nos equinos ${ }^{(13)}$.

Os músculos do braço incorporam-se ao úmero e inserem-se no antebraço. Os músculos que fazem parte do braço são o $\mathrm{m}$. bíceps do braço, $\mathrm{m}$. braquial, $\mathrm{m}$. tríceps do braço, $\mathrm{m}$. tensor da fáscia do antebraço e m. ancôneo.

O m. bíceps do braço (Figura 3. II G) está localizado na parte cranial do úmero de T. terrestris e está coberto pelo músculo peitoral. É um músculo forte, está envolto por uma fáscia espessa e está dividido tendinalmente em duas partes (superficial e profunda), assim como nos equinos ${ }^{(13)}$. Em Nasua nasua e em Procyon cancrivorus, segundo este músculo tem apenas uma parte ${ }^{(15,16)}$.

$\mathrm{O}$ m. braquial (Figura 3. II J) é volumoso e ocupa o sulco do músculo braquial do úmero. Inteiramente muscular ele cruza o $\mathrm{m}$. bíceps do braço até se fixar no antebraço. $\mathrm{O} \mathrm{m}$. tríceps do braço (Figura 3. I F e G e II I) em T. terrestris é o maior músculo desta região, ocupa o ângulo entre a margem caudal da escápula e úmero e está dividido em três cabeças principais e uma acessória, cabe ressaltar que a cabeça acessória está relacionada à cabeça medial, no entanto diferencia-se em função da direção de suas fibras, esta cabeça acessória também é descrita para caprinos ${ }^{(13)}$. A cabeça longa é a mais volumosa, triangular e espessa, e está coberta por uma grande aponeurose; a cabeça lateral é uma parte retangular e espessa, que está situada na parte lateral do braço, parcialmente coberta pelos músculos deltóide e redondo maior; a cabeça medial do $\mathrm{m}$. tríceps do braço está juntamente com a acessória na face medial do úmero, estendem-se do terço médio do úmero até o olécrano, imediatamente abaixo da cabeça da tuberosidade menor do úmero, assim como nos equinos, as origens e inserções coincidem ${ }^{(13)}$.

$\mathrm{O} \mathrm{m}$. tensor da fáscia do antebraço (Figura 3. II H) é uma faixa muscular estreita e triangular localizada nas faces medial e caudal do braço. Estende-se do terço proximal da margem caudal da 
escápula até a face medial do olécrano. Mesmo tendo o nome tensor da fáscia do antebraço este músculo não se associa à fáscia.

$\mathrm{O}$ m. ancôneo de $T$. terrestris é pequeno e alongado, se situa na face lateral do braço profundamente e é coberto pela cabeça lateral do $\mathrm{m}$. tríceps do braço. Em bovinos e equinos ${ }^{(13)}$, bem como em $T$. terrestris, este músculo está intimamente ligado à parte lateral do m. tríceps do braço.

Os músculos no extremo proximal do membro torácico servem para prover o braço de alavancas com importantes músculos impulsores. Assim como nos equinos, a longa alavanca muscular de $T$. terrestris fornece um passo maior por unidade de trabalho muscular. Estes fortes braços de alavanca, são bem adaptados para o desenvolvimento de força ${ }^{(13)}$.

O Quadro 1 e Figura 4 mostram os pontos de fixação (origem e inserção) e a inferência da ação dos músculos do cíngulo escapular e braço de T. terrestris, com base nos pontos de fixação, direção de fibras e o que é descrito pela literatura para outros animais.

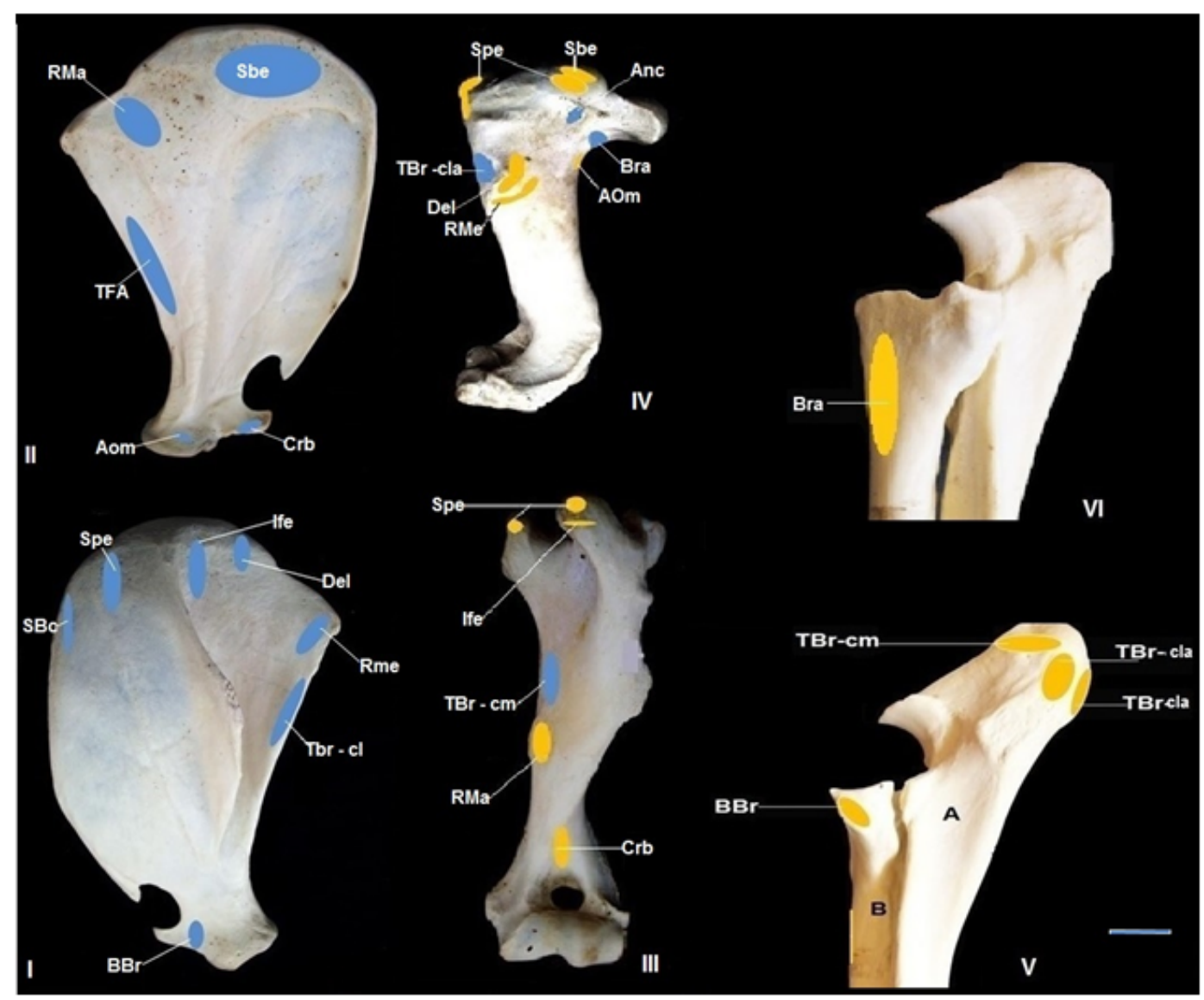

Figura 4: Fotografias dos pontos de fixação dos músculos do cíngulo escapular e braço de Tapirus terrestris. Amarelo: ponto de inserção muscular. Azul: ponto de origem muscular. (Fonte: Acervo particular. Uberlândia, 2013).

Legenda: I- Vista lateral da escápula - (BBr) $\mathrm{m}$. biceps do braço; (Del) $\mathrm{m}$. deltóide; (Ife) $\mathrm{m}$. infraespinhal; (RMe) $\mathrm{m}$. redondo menor; (Sbc) m. subclávio; (Spe) m. supraespinhal; (TBr-cl) músculo tríceps do braço cabeça longa. II-Vista medial da escápula - (AOm) m. articular do ombro; (Crb) m. coracobraquial; (RMa) m. redondo maior; (Sbe) $\mathrm{m}$. subescapular; (TFA) $\mathrm{m}$. tensor da fáscia do antebraço. III-Vista cranial do úmero - (Crb) $\mathrm{m}$. coracobraquial; (Ife) $\mathrm{m}$. infraespinhal; (RMa) m. redondo maior; (Spe) m. supraespinhal; (TBr-cm) m. tríceps do braço cabeça medial. IV-Vista lateral do úmero - (Anc) m. ancôneo; (AOm)m. articular do ombro; (Bra) m. braquial; (Del) m. deltóide; (RMe) $\mathrm{m}$. redondo menor; (Sbe) $\mathrm{m}$. subescapular; (Spe) $\mathrm{m}$. supraespinhal; (TBr-cla) $\mathrm{m}$. tríceps do braço cabeça lateral. V-Vista lateral da ulna (A) e rádio $(\mathrm{B})$ - $(\mathrm{BBr}) \mathrm{m}$. bíceps do braço; (TBr-cl) $\mathrm{m}$. tríceps do braço cabeça longa; (TBr-cla) $\mathrm{m}$. tríceps do braço cabeça lateral; (TBr-cm) tríceps do braço cabeça medial. VI: Vista Medial da ulna - (Bra) m. braquial. Barra de Calibração: $1 \mathrm{~cm}$ (figura real $\sim 35 \mathrm{~cm}$ ) 
Quadro 1: Origem, inserção e inferência da ação dos músculos do cíngulo escapular e braço de Tapirus terrestris

\begin{tabular}{|c|c|c|c|}
\hline $\begin{array}{l}\text { Músculos } \\
\text { escapulares } \\
\text { laterais }\end{array}$ & Origem & Inserção & Inferência de ação \\
\hline m. subclávio & Margem cranial da escápula & $\begin{array}{l}\text { Face profunda do } \mathrm{m} . \\
\text { braquiocefálico }\end{array}$ & $\begin{array}{l}\text { Manter o } \mathrm{m} \text {. braquiocefálico junto } \\
\text { à face lateral }\end{array}$ \\
\hline m. deltoide & $\begin{array}{l}\text { Margem cranial da escápula por } \\
\text { aponeurose }\end{array}$ & Tuberosidade deltóidea & $\begin{array}{l}\text { Flexionar a articulação do ombro e } \\
\text { abduzir o braço }\end{array}$ \\
\hline m. supraespinhal & $\begin{array}{l}\text { Cartilagem da escápula, distal à fossa } \\
\text { infraespinhal }\end{array}$ & $\begin{array}{l}\text { Tuberosidades maior } \mathrm{e} \\
\text { menor do úmero }\end{array}$ & Estender a articulação do ombro \\
\hline m. infraespinhal & $\begin{array}{l}\text { Cartilagem da escápula, distal à fossa } \\
\text { infraespinhal }\end{array}$ & $\begin{array}{l}\text { Tuberosidade maior do } \\
\text { úmero }\end{array}$ & $\begin{array}{l}\text { Abduzir o braço e girá-lo } \\
\text { lateralmente. }\end{array}$ \\
\hline m. redondo menor & $\begin{array}{l}\text { Parte caudal da fossa infraespinhal na } \\
\text { Margem caudal da escápula }\end{array}$ & $\begin{array}{l}\text { Imediatamente distal à } \\
\text { tuberosidade deltoidea, na } \\
\text { face medial do úmero }\end{array}$ & $\begin{array}{l}\text { Flexionar a articulação do ombro, } \\
\text { abduzir o braço e rotação lateral do } \\
\text { ombro }\end{array}$ \\
\hline $\begin{array}{l}\text { Músculos } \\
\text { escapulares } \\
\text { mediais }\end{array}$ & Origem & Inserção & Inferência de ação \\
\hline m. subescapular & $\begin{array}{l}\text { Fossa subescapular da escápula, na } \\
\text { margem cranial }\end{array}$ & $\begin{array}{l}\text { Tuberosidade menor do } \\
\text { úmero, em sua parte caudal }\end{array}$ & Aduzir o ombro \\
\hline m. redondo maior & $\begin{array}{l}\text { Face medial, na margem caudal na } \\
\text { região proximal da escápula }\end{array}$ & $\begin{array}{l}\text { Tuberosidade do } \mathrm{m} \text {. redondo } \\
\text { maior no úmero }\end{array}$ & $\begin{array}{l}\text { Flexionar a articulação do ombro e } \\
\text { aduzir o braço }\end{array}$ \\
\hline m. coracobraquial & Processo coracóide da escápula & $\begin{array}{l}\text { Face cranial do úmero, no } \\
\text { seu terço distal cranial à } \\
\text { fossa radial }\end{array}$ & $\begin{array}{l}\text { Aduzir o braço e flexionar a } \\
\text { articulação do ombro }\end{array}$ \\
\hline $\begin{array}{l}\text { m. articular do } \\
\text { ombro }\end{array}$ & Na parte caudal da cavidade glenoidal & $\begin{array}{l}\text { Superficie caudal do corpo } \\
\text { do úmero, distal ao colo }\end{array}$ & $\begin{array}{l}\text { Tencionar a cápsula de articulação } \\
\text { do ombro }\end{array}$ \\
\hline $\begin{array}{l}\text { Músculos do } \\
\text { braço }\end{array}$ & Origem & Inserção & Inferência de ação \\
\hline $\mathrm{m}$. bíceps do braço & $\begin{array}{l}\text { Ambas as partes na tuberosidade } \\
\text { supragleinodal }\end{array}$ & $\begin{array}{l}\text { Tuberosidade radial e fáscia } \\
\text { do antebraço }\end{array}$ & $\begin{array}{l}\text { Fixar o ombro e o cotovelo, } \\
\text { flexionar a articulação do cotovelo } \\
\text { e tencionar a fáscia do antebraço }\end{array}$ \\
\hline m. braquial & $\begin{array}{l}\text { Terço proximal da superficie caudal do } \\
\text { úmero }\end{array}$ & $\begin{array}{l}\text { Margem medial do rádio, } \\
\text { próximo ao ligamento } \\
\text { colateral }\end{array}$ & Flexionar a articulação do cotovelo \\
\hline \multirow{4}{*}{$\begin{array}{l}\text { m. tríceps do } \\
\text { braço }\end{array}$} & $\begin{array}{l}\text { Cabeça longa: margem caudal da } \\
\text { escápula }\end{array}$ & $\begin{array}{l}\text { Cabeça longa: parte caudal } \\
\text { da tuberosidade do olécrano }\end{array}$ & $\begin{array}{l}\text { Estender a articulação do cotovelo } \\
\text { e flexionar a articulação do ombro }\end{array}$ \\
\hline & $\begin{array}{l}\text { Cabeça lateral: tuberosidade deltoidea, } \\
\text { pela fáscia da articulação do cotovelo }\end{array}$ & $\begin{array}{l}\text { Cabeça lateral: superficie } \\
\text { lateral do olécrano }\end{array}$ & Estender a articulação do cotovelo \\
\hline & $\begin{array}{l}\text { Cabeça medial e cabeça acessória: } \\
\text { superficie medial do corpo do úmero, } \\
\text { distalmente a tuberosidade do } \mathrm{m} \text {. } \\
\text { redondo maior }\end{array}$ & $\begin{array}{l}\text { Cabeça medial: parte cranial } \\
\text { da tuberosidade do olécrano }\end{array}$ & Estender a articulação do cotovelo \\
\hline & $\begin{array}{l}\text { Cabeça acessória: superficie medial do } \\
\text { corpo do úmero }\end{array}$ & $\begin{array}{l}\text { Cabeça medial: parte cranial } \\
\text { da tuberosidade do olécrano }\end{array}$ & Estender a articulação do cotovelo \\
\hline $\begin{array}{l}\text { m. tensor da fáscia } \\
\text { do antebraço }\end{array}$ & $\begin{array}{l}\text { Margem caudal da escápula, por meio } \\
\text { do tendão grande dorsal }\end{array}$ & $\begin{array}{l}\text { Fáscia do antebraço, na } \\
\text { tuberosidade do olécrano }\end{array}$ & Estender a articulação do cotovelo \\
\hline m. ancôneo & $\begin{array}{l}\text { Superficie caudal, imediatamente distal } \\
\text { ao tuberosidade maior do úmero }\end{array}$ & $\begin{array}{l}\text { Superficie lateral do } \\
\text { olécrano }\end{array}$ & $\begin{array}{l}\text { Estender a articulação do cotovelo } \\
\text { e elevar a cápsula da articulação }\end{array}$ \\
\hline
\end{tabular}




\section{Conclusão}

Os ossos do cíngulo escapular e braço de T. terrestris têm acidentes específicos em comparação com outras espécies o que dá a este mamífero capacidade de deslocamentos em longas distâncias e suporte do peso. A escápula apresenta algumas diferenças em relação aos animais comparados, não possui acrômio e é ovalada, todavia, pode-se inferir que é mais similar à de Equus caballus. T. terrestris apresenta características ósseas e musculares de um animal adaptado ao deslocamento e a natação eventual com acidentes ósseos evidentes e musculatura desenvolvida. As principais diferenças morfológicas de $T$. terrestris corroboram para se inferir que a estrutura anatômica do cíngulo escapular e braço são adaptados funcionalmente para esta espécie.

\section{Referências}

1. Padilla M., Dowler RC. Tapirus terrestris. Mammalian Species, New York, v.2, no. 481, p. 1-8, 3 figs., 1994.

2. Medici EP. Flesher K, Beisiegel BM, Keuroghlian A, Desbiez ALJ, Gatti A, Pontes ARM, Campos CB, Tófoli CF, Junior EMM, Azevedo FCC, Pinho GM, Cordeiro JLP, Santos Júnior TS, Morais AA, Mangini PR, Rodrigues LF, Almeida LB. "Avaliação do risco de extinção da anta brasileira Tapirus terrestrisLinnaeus, 1758, no Brasil". Biodiversidade Brasileira. 2012;2(3):103-116.

3. Cozzuol MA, Clozato CL, Holanda EC, Rodrigues FHG, NienowS, Thoisy B, Redondo RAF, Santos FR. A new species of tapir from the Amazon. Journal of Mammalogy. 2013;94(6):1331-1345..

4. Ferreiro BS, Noriega JI. El Registro fossil de los tapires (Perissodactyla: Tapiridae) en al Pleistoceno de Entre Rios. Ameghinina. 2003;40(4, Suplemento): 84R,

5. Medici EP; Mangini PR; Fernandes-Santos RC. Health Assessment of Wild Lowland Tapir (Tapirus terrestris) Populations in the Atlantic Forest and Pantanal Biomes, Brazil (1996-2012). In: Journal of Wildlife Diseases. 2014;50(4):817-828.

6. Salas, LA. Habitat use by lowland tapir (Tapirus terrestris L.) in the Tabaro river valley, southern Venezuela. Canadian Journal of Zoology. 1996;74:1452-1458.

7. Holbrook, LT. "The unusual development of the sagittal crest in the Brazilian tapir (Tapirus terrestris)". Journal of Zoology. 2012;256(2):215-219

8. LIMA AR, Costa AM, Fioretto ET, Santiago HRV, Carmo DC, Branco E. Topografia do cone medular da preguiça. Pesq. Vet. Bras.[internet], 2011;31(7):627-630. Disponível em $<$ http://www.scielo.br/scielo.php?script=sci_arttext\&pid=S0100-736X2011000700014\&lng=en\&nrm=iso $>\quad$, acesso em abril de 2015.

9. Lima VM, Pereira FC, Pereira KF. Estudo Morfológico dos Músculos do Antebraço de Mão-Pelada, Procyon cancrivorus CUVIER, 1798. Bioscience Journal. 2010;26(1):109-114.

10. Varvruk JW. A importância do estudo da anatomia humana para o estudante da área de saúde. Faculdade de Medicina, Centro de Ciências da Saúde, Universidade Estadual de Maringá. O anatomista. 2012;3(2):4-35. Disponível em http://issuu.com/drhc/docs/o anatomista_volume22012? $=2371220 / 2718098$, acesso em abril de 2015 .

11. International Committee On Veterinary Gross Anatomical Nomenclature. Nomina anatomica veterinária. 5. ed. (rev.) Knoxville: World Association on Veterinary Anatomist, 2012. 177 p. Disponível em http://www.wava-amav.org/Downloads/nav_2012.pdf. Acesso em abril de 2015.

12. Fragoso JM. Tapir generated seed shadows: scale sepdendeent pachiness in teha amazon rain Forest. Journal of ecology, 85. 2007. 
13. Getty R, Sisson S, Grossman, JD. Anatomia dos Animais Domésticos. Rio de Janeiro: Guanabara Koogan, 5. Ed. v. 1. 1986. 1134 p.

14. Romão MF; Santos ALQ. Lima FC. Descriptive anatomy applied to the kinesiology and basic biomechanics of the pectoral girdle, stylopodium and zeugopodium muscles of broad snouted caiman Ciência. Rural [online]. 2013, vol.43, n.4 [cited 2015-03-24], pp. 631-638. Disponível em: $<\mathrm{http} / / /$ www.scielo.br/scielo.php?script=sci_arttext\&pid=S010384782013000400011\&lng=en\&nrm=iso>. Acesso: 10 de janeiro de 2014.

15. Santos AC, Bertassoli BM, Oliveira VC, Carvalho AF, Rosa RA, Manlaneres CAF. Morfologia dos músculos do ombro, braço e antebraço do quati (Nasua nasua Linnaeus, 1758). Revista Biotemas, 2010;23(3):165-173.

16. Santos AC, Bertassoli BM, Rosa RAA, Carvalho AF, Rosa RA, Manlaneres CAF. Miologia Comparada Do Membro Torácico Do Mão-pelada (Procyon Cancrivorus, G. CUVIER, 1798). Revista da FZVA.Uruguaiana. 2010;17(2):262-275.

17. Concha I, Adaro L, Borrón C, Altamirano C. Consideraciones anatómicas sobre la musculatura intrínseca del miembro torácico del puma (Puma concolor). International Journal of Morphology, 2004. 22 (2): 121-125. 